CLINICAL STUDY

\title{
Diabetes, metformin use, and colon cancer: a population-based cohort study in Taiwan
}

\author{
Chin-Hsiao Tseng \\ Department of Internal Medicine, National Taiwan University College of Medicine, Taipei, Taiwan and Division of Endocrinology and Metabolism, \\ Department of Internal Medicine, National Taiwan University Hospital, No. 7, Chung-Shan South Road, Taipei 100, Taiwan
}

(Correspondence should be addressed to $\mathrm{C}-\mathrm{H}$ Tseng at Department of Internal Medicine, National Taiwan University Hospital; Email: ccktsh@ms6.hinet.net)

\begin{abstract}
Objective: A retrospective cohort study, using a population-based reimbursement database, was conducted for investigating the relationship between diabetes and colon cancer and assessing whether metformin had a protective effect.

Methods: Overall, 493704 men and 502139 women, covered by the National Health Insurance, without colon cancer were followed from 2003 to 2005. Cox regression evaluated the adjusted relative risk (RR), considering confounders and detection examinations.

Results: Even though diabetes patients had a significantly higher probability of receiving examinations that could lead to the detection of colon cancer, they had a significantly higher risk $(24 \%)$ of this cancer after adjustment. Metformin users had a significantly lower risk $(27 \%)$ of colon cancer. While comparing patients with diabetes for $<1,1-3$, and $\geq 3$ years to nondiabetes individuals, the adjusted RR (95\% confidence interval) was 1.308 (1.020-1.679), 1.087 (0.900-1.313), and 1.185 (1.055-1.330) respectively. The higher risk among those with diabetes for $<1$ year suggested a possible reverse causality or a link with prediabetes. However, diabetes still might play some role in the development of colon cancer in those with diabetes for $\geq 3$ years. The duration of metformin use showed an inverse trend, with a significant RR of $0.643(0.490-0.845)$ in users for $\geq 3$ years, when compared with nonusers. In addition, metformin may reduce colon cancer risk associated with chronic obstructive pulmonary disease (a surrogate for smoking).

Conclusions: Following adjustment for potential detection bias and other covariates, diabetes remains a significant risk factor for colon cancer. Metformin may protect against colon cancer.
\end{abstract}

European Journal of Endocrinology 167 409-416

\section{Introduction}

Colon cancer is one of the leading causes of cancerrelated deaths in America (1), Europe (2), and Asia (3). Its incidence has been increasing rapidly in recent decades, and it is currently the second most common cause of cancer-related deaths in Taiwan (4). The abrupt increase in the incidence of colon cancer is probably related to factors such as obesity, a sedentary lifestyle, and the consumption of a Western diet with high fat and low fiber, all of which accompanied Taiwan's rapid economic growth (5).

Type 2 diabetes mellitus (T2DM) increases the risk for several types of cancers involving the liver, pancreas, colon, endometrium, bladder, and breast $(6,7,8,9,10,11)$. Insulin resistance, hyperinsulinemia, oxidative stress, and proinflammation have been suggested as the potential mechanisms $(7,8)$. Recent studies have suggested that different antidiabetic therapies may affect the diabetes patients' risk of developing cancer. Among them, insulin (12) and insulin secretagogues $(13,14)$ may increase this risk, but metformin $(15,16,17,18,19)$ and possibly thiazolidinedione (20) may reduce it.

Studies on the link between metformin and colon cancer are still sparse and the results are controversial. A recent systematic review and meta-analysis suggested that metformin was associated with a significant overall cancer risk reduction of $31 \%$ (21). However, its protective effect could only be demonstrated for pancreatic cancer and hepatocellular carcinoma, and the results were not significant for cancers involving the colon, breast, and prostate (21). In this meta-analysis, only three papers evaluated the effect of metformin on colon cancer risk specifically $(12,16,17)$ and the summary relative risk (RR; 95\% confidence interval) was 0.64 (0.38-1.08) (21). Another meta-analysis (19), which included a paper from Taiwan (15), estimated a significant summary RR of $0.63(0.47-0.84)$. On the other hand, a recent short-term clinical trial evaluating the effect of metformin $250 \mathrm{mg} /$ day $(n=12)$ vs no treatment $(n=14)$ in nondiabetic patients with rectal aberrant crypt foci (an endoscopic surrogate marker for 
colorectal cancer) for only 1 month found a significantly reduced number of aberrant crypt foci in metformintreated patients (22). This study strongly indicated a potential inhibitory effect of metformin on colorectal carcinogenesis. Currently, more than ten ongoing clinical trials are aimed at investigating the anticancer effects of metformin on various human malignancies involving the breast, prostate, pancreas, endometrium, kidney, lung, lymphoma, and others $(23,24)$.

A recent study conducted in the USA showed that diabetes patients, particularly in the first year of diagnosis, are more likely to receive endoscopic examinations of the lower gastrointestinal tract (25). This increases the likelihood that studies evaluating the link between diabetes and colon cancer, without considering the greater frequency of these clinical examinations in diabetes patients, might result in a biased overestimation of the incidence of colon cancer, especially among those with new-onset diabetes. Furthermore, it has not yet been fully evaluated whether the duration of metformin use is an important determinant in its association with colon cancer. Therefore, using the reimbursement databases of the National Health Insurance (NHI) of Taiwan, this study aimed to investigate: i) whether the link between T2DM and colon cancer is independent of detection bias; and ii) whether metformin and the duration of its use are associated with a protective effect against colon cancer.

\section{Materials and methods}

\section{Study population}

This is a population-based retrospective cohort study. According to the Ministry of Interior, Taiwan, in $2005,>98.0 \%$ of the Taiwanese population was covered by the NHI, a single-payer health insurance program launched on March 1, 1995. Each year, the Bureau of NHI collects data, including registration files and original claims data for reimbursement, and sends it to the National Health Research Institutes, as these are the only institutes approved for managing academic research databases. Then, the data files are de-identified by scrambling the identification codes of the patients and medical facilities for the protection of privacy. From January 1, 2005 to January 1, 2006, there were $\sim 25.68$ million beneficiaries in the NHI program according to the Registry for Beneficiaries data files. The National Health Research Institutes randomly sampled 1000000 beneficiaries from this registry file who were representative of the entire population and created the Longitudinal Health Insurance Database 2005 (LHID 2005). The reimbursement data files of these sampled individuals were compiled for use in academic research (26). The LHID 2005 was approved for use in this study, and the database contained all the longitudinal reimbursement information for the random sample from 1996 to the end of 2005. Information on sex, date of birth, medications, and diagnostic codes of all subjects based on the International Classification of Diseases, Ninth Revision, Clinical Modification (ICD-9-CM), were retrieved for analyses. Diabetes was coded 250.1-250.9 and colon cancer 153.

As colon cancer is rare in young people, we analyzed the data for all ages and for those aged $\geq 40$ years. Figure 1 shows a flowchart of the selection procedure used in this study. After exclusion of individuals with type 1 diabetes (in Taiwan, patients with type 1 diabetes were issued a 'Severe Morbidity Card' after certified diagnosis), individuals whose region of residence was unknown, and individuals diagnosed with

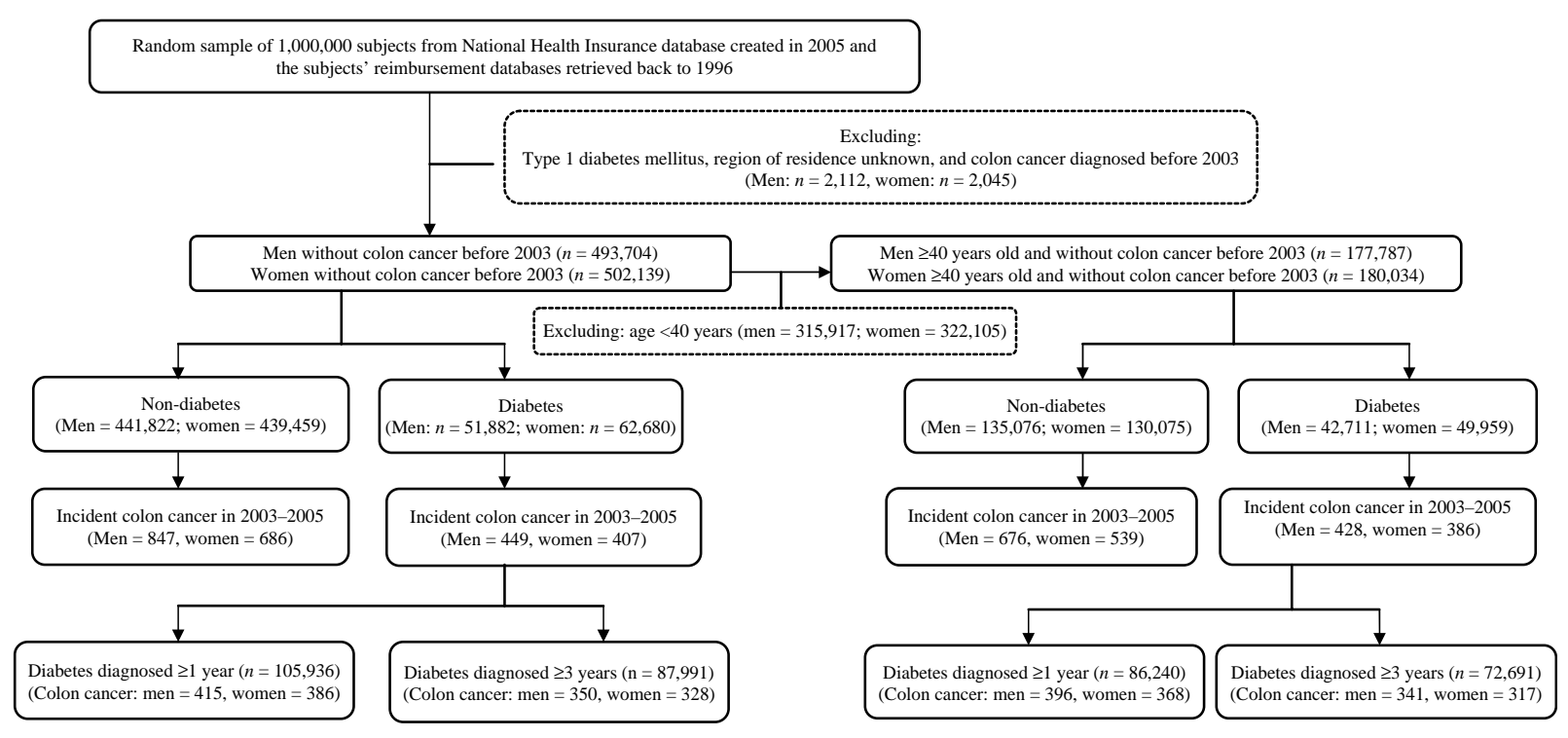

Figure 1 Flowchart showing the selection procedure of study subjects. 
colon cancer before 2003, 493704 men and 502139 women of all ages and 177787 men and 180034 women $\geq 40$ years old and without colon cancer were followed from January 1, 2003 to December 31, 2005.

\section{Statistical analyses}

Age, diabetes status, diabetes duration, and other covariates present in the reimbursement databases were determined as a status or a diagnosis on or before January 1, 2003. Colon cancer was only counted in cases in which the incidence occurred within the 3-year period from January 1, 2003 to December 31, 2005.

To compare whether the diabetes patients had a higher probability of receiving an examination to detect potential colon cancer than subjects without diabetes, the following examinations were performed by the $\chi^{2}$ test: i) abdominal sonography; ii) computed tomography and/or magnetic resonance imaging; iii) colofibroscopy; iv) tumor markers including carcinoembryonic antigen, carbohydrate antigen (CA) 19-9, CA-125, CA-153, and antisquamous cell carcinoma antigen; and $v$ ) any of the above.

Multivariable Cox regression models were created first to calculate the adjusted RRs for the following independent variables (diabetes/metformin status models): age, sex, diabetes status (yes vs no), dyslipidemia (ICD-9-CM codes: 272.0-272.4), obesity (278), hypertension (401-405), chronic obstructive pulmonary disease (COPD, 490-496, a surrogate for smoking), asthma (493), stroke (430-438), nephropathy (580-589), ischemic heart disease (410-414), peripheral arterial disease $(250.7,785.4,443.81$, and 440-448), eye disease $(250.5,362.0,369,366.41$, and 365.44), statins, fibrates, angiotensin-converting enzyme inhibitors and/or angiotensin receptor blockers, calcium channel blockers, aspirin, dipyridamole, clopidogrel/ticlopidine, nonsteroidal antiinflammatory drugs (NSAID), sulfonylurea, metformin, insulin (nonusers, users $<3$ years, and users $\geq 3$ years), acarbose, thiazolidinedione, region of residence, occupation, and potential colon cancer detection examinations. The region of residence, classified as Taipei, Northern, Central, Southern, and Kao-Ping/Eastern regions, served as a surrogate for geographical distribution of environmental exposure. Insured individuals were classified according to their occupation (a surrogate for socioeconomic status) as class I (civil servants, teachers, employees of governmental or private businesses, professionals, and technicians), class II (people without a specific employer, self-employed people, or seamen), class III (farmers or fishermen), and class IV (low-income families supported by social welfare or veterans).

To evaluate whether diabetes duration affected the RR, the independent variable of 'diabetes status' in the above 'diabetes/metformin status models' was re-categorized as 'no diabetes' (the referent group) and diabetes duration for $<1,1-3$, and $\geq 3$ years (diabetes duration models). To evaluate whether there was an association between metformin use and colon cancer risk, the duration of metformin use was categorized as $<1,1-3$, and $\geq 3$ years and the RR was compared with nonusers (metformin duration models). The other covariates entered into these regression models were the same as those in the 'diabetes/metformin status model'.

As smoking may also increase the risk of colon cancer (27), and a recent animal study suggested that metformin can prevent lung cancer induced by the tobacco carcinogen in A/J mice (28), we attempted to analyze whether metformin use would reduce or modify the risk of colon cancer associated with tobacco use by using COPD as a surrogate for smoking. Multivariable models were created to estimate the adjusted RRs for the joint effect of metformin use and COPD (metformin/COPD joint effect models) by dividing the subjects into four subgroups: i) group 1, metformin use $(+) /$ COPD $(-)$ (referent group); ii) group 2 , metformin use $(+) / \operatorname{COPD}(+)$; iii) group 3 , metformin use $(-) /$ COPD (-); and iv) group 4 , metformin use $(-) /$ COPD $(+)$. Interaction between metformin use and COPD was then assessed by adding the cross-product term in the models and determining the statistical significance of the coefficient for the interaction term (metformin/ COPD interaction models). The other independent variables entered into these models were the same as in the previous 'diabetes/metformin status model'.

Analyses were conducted using SAS Statistical Software, version 9.1 (SAS Institute, Cary, NC, USA). A $P$ value $<0.05$ was considered statistically significant.

\section{Results}

Table 1 compares the performance of clinical examinations that might potentially lead to the incident detection of colon cancer in diabetes patients and subjects without diabetes. The diabetes patients had a significantly higher probability of receiving clinical examinations that might potentially lead to the detection of colon cancer.

Table 2 shows the multivariable-adjusted RRs for colon cancer with regard to different independent variables in the 'diabetes/metformin status models'. Age, male sex, diabetes, COPD, ischemic heart disease, dyslipidemia, metformin, region of residence, and potential colon cancer detection examinations were significant predictors in either the model for all ages or age $\geq 40$ years. Nephropathy and NSAID users had a significantly higher risk for all ages, but the risk was not significant for subjects aged $\geq 40$ years.

Table 3 shows the additional Cox models. In the 'diabetes duration models', only those with new-onset diabetes ( $<1$ year) and those with diabetes for $\geq 3$ years had significantly higher risk of colon cancer. In the 'metformin duration models', even though an inverse 
Table 1 Comparison of examinations potentially leading to an incident diagnosis of colon cancer, in Taiwanese patients with and without diabetes mellitus, for all ages and age $\geq 40$ years.

\begin{tabular}{|c|c|c|c|c|c|}
\hline \multirow[b]{3}{*}{ Examination } & \multicolumn{4}{|c|}{ Diabetes mellitus } & \multirow[b]{3}{*}{$P$ value } \\
\hline & \multicolumn{2}{|c|}{ No } & \multicolumn{2}{|c|}{ Yes } & \\
\hline & $n$ & Percentage (\%) & $n$ & Percentage (\%) & \\
\hline \multicolumn{6}{|c|}{ Abdominal sonography } \\
\hline \multicolumn{6}{|c|}{ All ages } \\
\hline No & 828952 & 89.45 & 97735 & 10.55 & \multirow[t]{2}{*}{$<0.0001$} \\
\hline Yes & 52349 & 75.67 & 16832 & 24.33 & \\
\hline \multicolumn{6}{|c|}{ Age $\geq 40$ years } \\
\hline No & 280988 & 77.33 & 82389 & 22.67 & \multirow[t]{2}{*}{$<0.0001$} \\
\hline Yes & 31540 & 67.69 & 15054 & 32.31 & \\
\hline \multicolumn{6}{|l|}{ CT/MRI } \\
\hline All ages & & & & & \\
\hline No & 880994 & 88.50 & 114449 & 11.50 & \multirow[t]{2}{*}{$<0.0001$} \\
\hline Yes & 307 & 72.24 & 118 & 27.76 & \\
\hline \multicolumn{6}{|c|}{ Age $\geq 40$ years } \\
\hline No & 312304 & 76.24 & 97336 & 23.76 & \multirow[t]{2}{*}{0.0003} \\
\hline Yes & 224 & 67.67 & 107 & 32.33 & \\
\hline \multicolumn{6}{|l|}{ Colofibroscopy } \\
\hline All ages & & & & & \\
\hline No & 868008 & 88.93 & 108039 & 11.07 & \multirow[t]{2}{*}{$<0.0001$} \\
\hline Yes & 13293 & 67.07 & 6528 & 32.93 & \\
\hline \multicolumn{6}{|c|}{ Age $\geq 40$ years } \\
\hline No & 302433 & 76.82 & 91277 & 23.18 & \multirow{2}{*}{$<0.0001$} \\
\hline Yes & 10095 & 62.08 & 6166 & 37.92 & \\
\hline \multicolumn{6}{|l|}{ Tumor markers } \\
\hline All ages & & & & & \\
\hline No & 871837 & 88.60 & 112163 & 11.40 & \multirow[t]{2}{*}{$<0.0001$} \\
\hline Yes & 9464 & 79.74 & 2404 & 20.26 & \\
\hline \multicolumn{6}{|c|}{ Age $\geq 40$ years } \\
\hline No & 307924 & 76.31 & 95615 & 23.69 & \multirow[t]{2}{*}{$<0.0001$} \\
\hline Yes & 4604 & 71.58 & 1828 & 28.42 & \\
\hline \multicolumn{6}{|c|}{ Any of the above } \\
\hline All ages & & & & & \\
\hline No & 811621 & 89.86 & 91617 & 10.14 & \multirow[t]{2}{*}{$<0.0001$} \\
\hline Yes & 69680 & 75.22 & 22950 & 24.78 & \\
\hline \multicolumn{6}{|c|}{ Age $\geq 40$ years } \\
\hline No & 270335 & 77.83 & 77005 & 22.17 & \multirow[t]{2}{*}{$<0.0001$} \\
\hline Yes & 42193 & 67.37 & 20438 & 32.63 & \\
\hline
\end{tabular}

$\mathrm{CT}$, computed tomography; MRI, magnetic resonance imaging.

trend was observed in the risk of colon cancer with a longer duration of metformin use, only users for $\geq 3$ years would have a significantly lower risk of $\sim 35 \%$. In the 'metformin/COPD joint effect models', when compared with the referent group (those who used metformin and did not have COPD), the risk was only significantly higher for those who did not use metformin and had COPD simultaneously. For those who used metformin, the risk was not significantly different between patients with and without COPD. The $P$ value for the interaction term was not significant $(P>0.1)$ in the 'metformin/COPD interaction model' either for all ages or for those aged $\geq 40$ years (data not shown).

\section{Discussion}

This study showed that even though patients with diabetes may have a higher probability of receiving examinations that could lead to an incident detection of colon cancer (Table 1), as reported by Lewis et al. (25), the risk of colon cancer in patients with diabetes remained significantly higher than that in the subjects without diabetes in the Cox regression analyses, after adjustment for confounders and these examinations (Table 2). Furthermore, metformin use was consistently associated with a lower risk of colon cancer (Tables 2 and 3), especially with use for $\geq 3$ years (Table 3). The use of metformin also reduced the risk of colon cancer related to smoking when COPD was used as a surrogate (Table 3), but there was no significant interaction between metformin use and COPD on colon cancer risk.

Diabetes was not the only chronic disease linked to colon cancer; a variety of comorbidities such as COPD (a surrogate for smoking), nephropathy, ischemic heart disease, and dyslipidemia were also associated with a higher risk for colon cancer (Table 2). This strongly suggested that the common pathological changes 
Table 2 Adjusted relative risks for colon cancer derived from Cox proportional hazard regression in the 'diabetes/metformin status models'.

\begin{tabular}{|c|c|c|c|c|c|c|c|c|c|}
\hline \multirow[b]{2}{*}{ Variables } & \multirow[b]{2}{*}{ Interpretation } & \multirow{2}{*}{$\begin{array}{l}\text { Colon } \\
\text { cancer } \\
\text { cases }(n)\end{array}$} & \multicolumn{3}{|c|}{ All ages } & \multirow{2}{*}{$\begin{array}{l}\text { Colon } \\
\text { cancer } \\
\text { cases }(n)\end{array}$} & \multicolumn{3}{|c|}{ Age $\geq \mathbf{4 0}$ years } \\
\hline & & & $\mathrm{RR}$ & $95 \% \mathrm{Cl}$ & $P$ value & & $\mathrm{RR}$ & $95 \% \mathrm{Cl}$ & $P$ value \\
\hline Age & $\begin{array}{c}\text { Every 1-year } \\
\text { increment }\end{array}$ & 2389 & 1.055 & $(1.052,1.058)$ & $<0.0001$ & 2029 & 1.042 & $(1.038,1.046)$ & $<0.0001$ \\
\hline Sex & Men vs women & $1296 / 1093$ & 1.286 & $(1.185,1.396)$ & $<0.0001$ & $1104 / 925$ & 1.270 & $(1.162,1.389)$ & $<0.0001$ \\
\hline Diabetes & Yes vs no & $678 / 1711$ & 1.243 & $(1.105,1.399)$ & 0.0003 & $658 / 1371$ & 1.274 & $(1.129,1.437)$ & $<0.0001$ \\
\hline Hypertension & Yes vs no & $943 / 1446$ & 0.903 & $(0.805,1.013)$ & 0.0828 & $931 / 1098$ & 0.949 & $(0.844,1.067)$ & 0.3848 \\
\hline COPD & Yes vs no & $843 / 1546$ & 1.214 & $(1.093,1.349)$ & 0.0003 & $779 / 1250$ & 1.231 & $(1.102,1.375)$ & 0.0002 \\
\hline Asthma & Yes vs no & $320 / 2069$ & 0.930 & $(0.809,1.069)$ & 0.3063 & 299/1730 & 0.965 & $(0.835,1.115)$ & 0.6274 \\
\hline Stroke & Yes vs no & $362 / 2027$ & 0.960 & $(0.845,1.091)$ & 0.5351 & $358 / 1671$ & 1.018 & $(0.894,1.159)$ & 0.7886 \\
\hline Nephropathy & Yes vs no & $283 / 2106$ & 1.148 & $(1.007,1.309)$ & 0.0385 & $262 / 1767$ & 1.123 & $(0.980,1.286)$ & 0.0952 \\
\hline $\begin{array}{l}\text { Ischemic heart } \\
\text { disease }\end{array}$ & Yes vs no & $608 / 1781$ & 1.179 & $(1.050,1.324)$ & 0.0054 & $595 / 1434$ & 1.197 & $(1.064,1.347)$ & 0.0028 \\
\hline $\begin{array}{l}\text { Peripheral } \\
\text { arterial disease }\end{array}$ & Yes vs no & $203 / 2186$ & 1.125 & $(0.966,1.311)$ & 0.1297 & 197/1832 & 1.131 & $(0.969,1.321)$ & 0.1197 \\
\hline Eye disease & Yes vs no & $75 / 2314$ & 1.097 & $(0.848,1.417)$ & 0.4812 & $75 / 1954$ & 1.146 & $(0.885,1.484)$ & 0.2999 \\
\hline Dyslipidemia & Yes vs no & $552 / 1837$ & 1.213 & $(1.079,1.363)$ & 0.0012 & $528 / 1501$ & 1.161 & $(1.030,1.309)$ & 0.0146 \\
\hline Obesity & Yes vs no & $14 / 2375$ & 0.992 & $(0.586,1.681)$ & 0.9777 & 9/2020 & 0.708 & $(0.367,1.365)$ & 0.3029 \\
\hline Statin & Yes vs no & $202 / 2187$ & 1.043 & $(0.884,1.231)$ & 0.6146 & $198 / 1831$ & 1.056 & $(0.893,1.248)$ & 0.5246 \\
\hline Fibrate & Yes vs no & $202 / 2187$ & 0.915 & $(0.778,1.076)$ & 0.2817 & $196 / 1833$ & 0.901 & $(0.764,1.062)$ & 0.2129 \\
\hline $\begin{array}{l}\text { ACE inhibitor/ } \\
\text { ARB }\end{array}$ & Yes vs no & $270 / 2119$ & 1.075 & $(0.921,1.255)$ & 0.3566 & $269 / 1760$ & 1.071 & $(0.917,1.250)$ & 0.3877 \\
\hline $\begin{array}{l}\text { Calcium channel } \\
\text { blocker }\end{array}$ & Yes vs no & $270 / 2119$ & 1.039 & $(0.891,1.211)$ & 0.6259 & $270 / 1759$ & 1.044 & $(0.895,1.218)$ & 0.5835 \\
\hline Aspirin & Yes vs no & $657 / 1732$ & 1.017 & $(0.912,1.133)$ & 0.7633 & $614 / 1415$ & 1.034 & $(0.922,1.161)$ & 0.5649 \\
\hline Dipyridamole & Yes vs no & $597 / 1792$ & 0.961 & $(0.857,1.078)$ & 0.4986 & $584 / 1445$ & 0.990 & $(0.881,1.112)$ & 0.8635 \\
\hline $\begin{array}{l}\text { Clopidogrel/ } \\
\text { ticlopidine }\end{array}$ & Yes vs no & $47 / 2342$ & 0.901 & $(0.669,1.215)$ & 0.4955 & $47 / 1982$ & 0.923 & $(0.685,1.244)$ & 0.8986 \\
\hline NSAID & Yes vs no & $2272 / 117$ & 1.371 & $(1.133,1.659)$ & 0.0012 & 1930/99 & 1.139 & $(0.925,1.402)$ & 0.2193 \\
\hline Sulfonylurea & Yes vs no & $274 / 2115$ & 1.048 & $(0.849,1.293)$ & 0.6642 & $267 / 1762$ & 1.007 & $(0.812,1.248)$ & 0.9517 \\
\hline Metformin & Yes vs no & $206 / 2183$ & 0.731 & $(0.580,0.921)$ & 0.0078 & 203/1826 & 0.739 & $(0.584,0.934)$ & 0.0115 \\
\hline \multirow[t]{2}{*}{ Insulin } & $<3$ years vs no & $17 / 2364$ & 0.909 & $(0.553,1.495)$ & 0.7067 & $17 / 2004$ & 0.909 & $(0.552,1.497)$ & 0.7082 \\
\hline & $\geq 3$ years vs no & $8 / 2364$ & 1.729 & $(0.853,3.505)$ & 0.1290 & 8/2004 & 1.657 & $(0.816,3.365)$ & 0.1627 \\
\hline Acarbose & Yes vs no & $27 / 2362$ & 1.255 & $(0.827,1.906)$ & 0.2863 & $27 / 2002$ & 1.258 & $(0.828,1.912)$ & 0.2819 \\
\hline Pioglitazone & Yes vs no & $3 / 2386$ & 0.784 & $(0.247,2.494)$ & 0.6808 & $3 / 2026$ & 0.789 & $(0.248,2.509)$ & 0.6885 \\
\hline Rosiglitazone & Yes vs no & $29 / 2360$ & 1.218 & $(0.808,1.838)$ & 0.3460 & $29 / 2000$ & 1.202 & $(0.797,1.814)$ & 0.3803 \\
\hline \multirow[t]{4}{*}{$\begin{array}{l}\text { Region of } \\
\text { residence }\end{array}$} & $\begin{array}{l}\text { Northern vs } \\
\text { Taipei }\end{array}$ & $446 / 1041$ & 1.118 & $(0.998,1.252)$ & 0.0536 & $362 / 858$ & 1.108 & $(0.977,1.256)$ & 0.1112 \\
\hline & Central vs Taipei & $306 / 1041$ & 0.576 & $(0.505,0.656)$ & $<0.0001$ & $261 / 858$ & 0.583 & $(0.505,0.673)$ & $<0.0001$ \\
\hline & $\begin{array}{l}\text { Southern vs } \\
\text { Taipei }\end{array}$ & $309 / 1041$ & 0.651 & $(0.569,0.745)$ & $<0.0001$ & $285 / 858$ & 0.695 & $(0.602,0.802)$ & $<0.0001$ \\
\hline & $\begin{array}{l}\text { Kao-Ping/ } \\
\text { Eastern vs } \\
\text { Taipei }\end{array}$ & $287 / 1041$ & 0.528 & $(0.462,0.604)$ & $<0.0001$ & $263 / 858$ & 0.563 & $(0.488,0.648)$ & $<0.0001$ \\
\hline \multirow[t]{3}{*}{ Occupation } & II vs I & $384 / 909$ & 1.124 & $(0.998,1.268)$ & 0.0549 & $328 / 679$ & 1.044 & $(0.914,1.192)$ & 0.5273 \\
\hline & III vs I & $531 / 909$ & 1.075 & $(0.953,1.212)$ & 0.2424 & $503 / 679$ & 1.110 & $(0.976,1.262)$ & 0.1116 \\
\hline & IV vs I & $565 / 909$ & 0.983 & $(0.879,1.098)$ & 0.7575 & $519 / 679$ & 1.048 & $(0.929,1.182)$ & 0.4479 \\
\hline $\begin{array}{l}\text { Potential colon } \\
\text { cancer detection } \\
\text { examinations }\end{array}$ & Yes vs no & $642 / 1747$ & 1.884 & $(1.714,2.071)$ & $<0.0001$ & $557 / 1472$ & 1.715 & $(1.549,1.898)$ & $<0.0001$ \\
\hline
\end{tabular}

$\mathrm{RR}$, relative risk; $\mathrm{Cl}$, confidence interval; $\mathrm{ACE}$ inhibitor, angiotensin-converting enzyme inhibitor; $\mathrm{ARB}$, angiotensin receptor blocker; refer to Materials and methods section for the categories of occupation.

associated with these conditions, such as insulin resistance, hyperinsulinemia, oxidative stress, and proinflammatory state, may underline the development of colon cancer. The link with these chronic comorbidities also suggested a complicated scenario in the study of the link between diabetes and colon cancer because at different diabetes stages these comorbidities may set in and influence the association. These comorbidities should also be considered and adjusted for in future studies evaluating the risk of developing colon cancer.

The $\sim 30 \%$ higher risk of developing colon cancer associated with new-onset diabetes (diabetes duration 
Table 3 Additional Cox proportional hazard regression models for relative risk for colon cancer. Only the relative risks for diabetes durations, duration of metformin use, and the joint effect of metformin use and COPD in the above models are shown. The other variables adjusted are the same as that shown in the 'diabetes/metformin status models' in Table 2.

\begin{tabular}{|c|c|c|c|c|c|c|c|c|c|}
\hline \multirow[b]{2}{*}{ Variables } & \multirow[b]{2}{*}{ Interpretation } & \multirow[b]{2}{*}{$n / N$} & \multicolumn{3}{|c|}{ All ages } & \multirow[b]{2}{*}{$n / N$} & \multicolumn{3}{|c|}{ Age $\geq \mathbf{4 0}$ years } \\
\hline & & & $\mathrm{RR}$ & $95 \% \mathrm{Cl}$ & $P$ value & & $\mathrm{RR}$ & $95 \% \mathrm{Cl}$ & $P$ value \\
\hline \multicolumn{10}{|l|}{$\begin{array}{l}\text { Diabetes } \\
\text { duration } \\
\text { models }\end{array}$} \\
\hline \multirow{4}{*}{$\begin{array}{l}\text { Diabetes } \\
\text { duration }\end{array}$} & No diabetes & $1711 / 907852$ & 1.000 & & & $1371 / 285130$ & 1.000 & & \\
\hline & $<1$ year & $66 / 9380$ & 1.308 & $(1.020,1.679)$ & 0.0347 & $65 / 7228$ & 1.349 & $(1.049,1.736)$ & 0.0197 \\
\hline & $1-3$ years & $123 / 19569$ & 1.087 & $(0.900,1.313)$ & 0.3844 & $119 / 15375$ & 1.101 & $(0.908,1.334)$ & 0.3279 \\
\hline & $\geq 3$ years & $489 / 59042$ & 1.185 & $(1.055,1.330)$ & 0.0042 & $474 / 50088$ & 1.193 & $(1.060,1.344)$ & 0.0036 \\
\hline \multicolumn{10}{|l|}{$\begin{array}{l}\text { Metformin } \\
\text { duration } \\
\text { models }\end{array}$} \\
\hline \multirow{4}{*}{$\begin{array}{c}\text { Metformin } \\
\text { duration }\end{array}$} & Nonusers & $472 / 61009$ & 1.000 & & & $455 / 47538$ & 1.000 & & \\
\hline & $<1$ year & $29 / 3973$ & 0.876 & $(0.590,1.301)$ & 0.5109 & $29 / 3508$ & 0.896 & $(0.603,1.333)$ & 0.5893 \\
\hline & $1-3$ years & $56 / 7229$ & 0.859 & $(0.629,1.173)$ & 0.3396 & $54 / 6516$ & 0.843 & $(0.613,1.159)$ & 0.2933 \\
\hline & $\geq 3$ years & $121 / 15780$ & 0.643 & $(0.490,0.845)$ & 0.0015 & $120 / 15129$ & 0.646 & $(0.490,0.852)$ & 0.0020 \\
\hline \multicolumn{10}{|c|}{$\begin{array}{l}\text { Metformin/ } \\
\text { COPD joint } \\
\text { effect models }\end{array}$} \\
\hline \multirow[t]{4}{*}{$\begin{array}{l}\text { Metformin/ } \\
\text { COPD }\end{array}$} & $\begin{array}{l}\text { Metformin }(+) \\
\text { /COPD }(-)\end{array}$ & $114 / 17659$ & 1.000 & & & $111 / 16152$ & 1.000 & & \\
\hline & $\begin{array}{l}\text { Metformin }(+) \\
\text { /COPD }(+)\end{array}$ & $92 / 9323$ & 1.086 & $(0.820,1.438)$ & 0.5660 & $92 / 9001$ & 1.124 & $(0.847,1.492)$ & 0.4181 \\
\hline & $\begin{array}{l}\text { Metformin }(-) \\
\text { /COPD }(-)\end{array}$ & $1432 / 807170$ & 1.248 & $(0.955,1.632)$ & 0.1046 & $1139 / 255242$ & 1.241 & $(0.944,1.632)$ & 0.1214 \\
\hline & $\begin{array}{l}\text { Metformin }(-) \\
\text { /COPD }(+)\end{array}$ & $751 / 161691$ & 1.548 & $(1.176,2.036)$ & 0.0018 & $687 / 77426$ & 1.560 & $(1.178,2.065)$ & 0.0019 \\
\hline
\end{tabular}

$n$, number of cases of colon cancer; $N$, number of cases followed; RR, relative risk; $\mathrm{Cl}$, confidence interval. The $P$ value for the interaction term of metformin and COPD was not significant $(P>0.1)$ in the 'metformin/COPD interaction model' for either all ages or age $\geq 40$ years.

$<1$ year), as shown in the 'diabetes duration models' of Table 3, may argue against a causal role of diabetes in the development of colon cancer in these patients due to the brevity of the diabetes period. Detection bias might play some role during this time and a reverse causality of abnormal glucose metabolism induced by colon cancer could not be excluded. However, this might also indicate a link between prediabetes and colon cancer as the presence of insulin resistance with hyperinsulinemia before the onset of diabetes may significantly increase the risk of cancer $(7,8)$. The $\sim 20 \%$ higher risk of colon cancer associated with diabetes for $\geq 3$ years in the 'diabetes duration models' (Table 3) suggested a potential causal link with diabetes in these patients, as the diabetes was diagnosed at least 3 years before the colon cancer and would probably not be a consequence of the carcinogenic process.

The use of insulin (12), insulin secretagogues $(13,14,15)$, or thiazolidinedione $(19,20)$ may also affect cancer risk. In this study, except for metformin, we could not identify any significant association with other antidiabetic therapies and colon cancer (Table 2). However, though not statistically significant, the use of insulin for $\geq 3$ years was associated with a more than $60 \%$ higher risk of colon cancer (Table 2). Further in-depth analyses would be worthwhile to explore this insulin effect on colon cancer. The lower risk of colon cancer associated with metformin use (Tables 2 and 3) was in agreement with the earlier meta-analyses $(19,21)$ and supported the preliminary clinical trial by Hosono et al. (22). Together, these studies provided a strong rationale for undertaking larger clinical trials to investigate the cancer-protecting effects of metformin on various human malignancies including colon cancer $(23,24)$.

The higher risk of colon cancer associated with NSAID use in the analyses carried out for all ages (Table 2) probably reflected a preexisting higher inflammatory condition associated with their use. However, this association was not significant when the analyses were conducted for those aged $\geq 40$ years (Table 2). We did not carry out in-depth analyses for the role of these drugs because it was not the main theme of this study.

Living in the Northern or Metropolitan Taipei region (the two most urbanized regions in Taiwan) was associated with a significantly higher risk of colon cancer than was living in other regions. This was compatible with the common concept that colon cancer is a disease related to a Westernized lifestyle (5). On the other hand, occupation was not significantly associated with colon cancer risk. This implied that socioeconomic status or income might not be a significant risk factor. As cancer is associated with a severe morbidity and most medical copayments can be waived for those insured with NHI, it was unlikely that there would be different detection rates among the social classes. 
This study has several strengths. It is a populationbased study with a large and nationally representative sample. Therefore, the findings of this study can be generalized to the population of Taiwan. However, generalization of the study findings to other ethnicities should be reconfirmed. The database included outpatients and inpatients, and we included diagnoses of both sets of patients. The use of medical records reduced the bias related to self-reporting. Finally, we excluded patients with type 1 diabetes to demonstrate a link with T2DM.

This study also has a few limitations. We did not have biochemical data such as glucose, insulin, HbA1c, or lipid levels to evaluate their potential effects. Some potential confounders such as anthropometric factors, dietary factors, physical activity, family history, and genetic parameters were not measured, and we used COPD as a surrogate for smoking. As this is an observational study, an experimental design will be needed to confirm the protective effect of metformin use on the development of colon cancer.

In summary, this study confirms a higher risk of colon cancer in patients with T2DM despite the existence of a detection bias. Furthermore, the results support that a protective effect of metformin on the development of colon cancer, and metformin use may protect against the colon cancer associated with smoking when COPD is used as a surrogate marker.

\section{Declaration of interest}

The authors declare that there is no conflict of interest that could be perceived as prejudicing the impartiality of the research reported.

\section{Funding}

The study was supported by the Department of Health of Taiwan (DOH97-TD-D-113-97009). The funder had no role in the analyses or the writing of the manuscript.

\section{Author contribution statement}

C-H Tseng researched the data and wrote the manuscript.

\section{References}

1 Edwards BK, Ward E, Kohler BA, Eheman C, Zauber AG, Anderson RN, Jemal A, Schymura MJ, Lansdorp-Vogelaar I, Seeff LC, van Ballegooijen M, Goede SL \& Ries LA. Annual report to the nation on the status of cancer, 1975-2006, featuring colorectal cancer trends and impact of interventions (risk factors, screening, and treatment) to reduce future rates. Cancer 2010116 544-573. (doi:10.1002/cncr.24760)

2 La Vecchia C, Bosetti C, Lucchini F, Bertuccio P, Negri E, Boyle P \& Levi F. Cancer mortality in Europe, 2000-2004, and an overview of trends since 1975. Annals of Oncology 201021 1323-1360. (doi:10.1093/annonc/mdp530)

3 Hyodo I, Suzuki H, Takahashi K, Saito Y, Tanaka S, Chiu HM, Kim NK, Li J, Lim R, Villalon A \& Boku N. Present status and perspectives of colorectal cancer in Asia: Colorectal Cancer
Working Group report in 30th Asia-Pacific Cancer Conference. Japanese Journal of Clinical Oncology 201040 (Suppl 1) i38-i43. (doi:10.1093/jjco/hyq125)

4 Bureau of Health Promotion. Cancer Registry Annual Report, 2008, Taiwan. http://www1.cgmh.org.tw/lhcc/file/01.news/1000413ca. pdf (accessed 22 April 2011).

5 Giouleme O, Diamantidis MD \& Katsaros MG. Is diabetes a causal agent for colorectal cancer? Pathophysiological and molecular mechanisms. World Journal of Gastroenterology 201117 444-448. (doi:10.3748/wjg.v17.i4.444)

6 Larsson SC, Orsini N \& Wolk A. Diabetes mellitus and risk of colorectal cancer: a meta-analysis. Journal of the National Cancer Institute 200597 1679-1687. (doi:10.1093/jnci/dji375)

7 Giovannucci E \& Michaud D. The role of obesity and related metabolic disturbances in cancers of the colon, prostate, and pancreas. Gastroenterology 2007132 2208-2225. (doi:10.1053/ j.gastro.2007.03.050)

8 Giovannucci E, Harlan DM, Archer MC, Bergenstal RM, Gapstur SM, Habel LA, Pollak M, Regensteiner JG \& Yee D. Diabetes and cancer: a consensus report. Diabetes Care 201033 1674-1685. (doi:10.2337/dc10-0666)

9 Tseng CH, Chong CK, Tseng CP \& Chan TT. Age-related risk of mortality from bladder cancer in diabetic patients: a 12-year follow-up of a national cohort in Taiwan. Annals of Medicine 2009 41 371-379. (doi:10.1080/07853890902729778)

10 Tseng $\mathrm{CH}$. Diabetes and risk of bladder cancer: a study using the National Health Insurance database in Taiwan. Diabetologia 2011 54 2009-2015. (doi:10.1007/s00125-011-2171-z)

11 Tseng CH, Chong CK \& Tai TY. Secular trend for mortality from breast cancer and the association between diabetes and breast cancer in Taiwan between 1995 and 2006. Diabetologia 200952 240-246. (doi:10.1007/s00125-008-1204-8)

12 Yang YX, Hennessy S \& Lewis JD. Insulin therapy and colorectal cancer risk among type 2 diabetes mellitus patients. Gastroenterology 2004127 1044-1050. (doi:10.1053/j.gastro.2004. 07.011)

13 Hemkens LG, Grouven U, Bender R, Günster C, Gutschmidt S, Selke GW \& Sawicki PT. Risk of malignancies in patients with diabetes treated with human insulin or insulin analogues: a cohort study. Diabetologia 200952 1732-1744. (doi:10. 1007/s00125-009-1418-4)

14 Jonasson JM, Ljung R, Talbäck M, Haglund B, Gudbjörnsdòttir S \& Steineck G. Insulin glargine use and short-term incidence of malignancies - a population-based follow-up study in Sweden. Diabetologia 200952 1745-1754. (doi:10.1007/s00125-0091444-2)

15 Lee MS, Hsu CC, Wahlqvist ML, Tsai HN, Chang YH \& Huang YC. Type 2 diabetes increases and metformin reduces total, colorectal, liver and pancreatic cancer incidences in Taiwanese: a representative population prospective cohort study of 800,000 individuals. BMC Cancer 201111 20. (doi:10.1186/1471-2407-11-20)

16 Currie CJ, Poole CD \& Gale EA. The influence of glucose-lowering therapies on cancer risk in type 2 diabetes. Diabetologia 200952 1766-1777. (doi:10.1007/s00125-009-1440-6)

17 Libby G, Donnelly LA, Donnan PT, Alessi DR, Morris AD \& Evans JM. New users of metformin are at low risk of incident cancer: a cohort study among people with type 2 diabetes. Diabetes Care 200932 1620-1625. (doi:10.2337/dc08-2175)

18 Landman GW, Kleefstra N, van Hateren KJ, Groenier KH, Gans RO \& Bilo HJ. Metformin associated with lower cancer mortality in type 2 diabetes: ZODIAC-16. Diabetes Care 201033 322-326. (doi:10.2337/dc09-1380)

19 Zhang ZJ, Zheng ZJ, Kan H, Song Y, Cui W, Zhao G \& Kip KE. Reduced risk of colorectal cancer with metformin therapy in patients with type 2 diabetes: a meta-analysis. Diabetes Care 2011 34 2323-2328. (doi:10.2337/dc11-0512)

20 Okumura T. Mechanisms by which thiazolidinediones induce anti-cancer effects in cancers in digestive organs. Journal of Gastroenterology 201045 1097-1102. (doi:10.1007/s00535010-0310-9) 
21 Decensi A, Puntoni M, Goodwin P, Cazzaniga M, Gennari A, Bonanni B \& Gandini S. Metformin and cancer risk in diabetic patients: a systematic review and meta-analysis. Cancer Prevention Research 20103 1451-1461. (doi:10.1158/1940-6207.CAPR10-0157)

22 Hosono K, Endo H, Takahashi H, Sugiyama M, Sakai E, Uchiyama T, Suzuki K, Iida H, Sakamoto Y, Yoneda K, Koide T, Tokoro C, Abe Y, Inamori M, Nakagama H \& Nakajima A. Metformin suppresses colorectal aberrant crypt foci in a shortterm clinical trial. Cancer Prevention Research 20103 1077-1083. (doi:10.1158/1940-6207.CAPR-10-0186)

23 Kourelis TV \& Siegel RD. Metformin and cancer: new applications for an old drug. Medical Oncology 201229 1314-1327. (doi:10.1007/s12032-011-9846-7)

24 Guppy A, Jamal-Hanjani M \& Pickering L. Anticancer effects of metformin and its potential use as a therapeutic agent for breast cancer. Future Oncology 20117 727-736. (doi:10.2217/fon.11.49)

25 Lewis JD, Capra AM, Achacoso NS, Ferrara A, Levin TR, Quesenberry CP Jr \& Habel LA. Medical therapy for diabetes is associated with increased use of lower endoscopy. Pharmacoepidemiology and Drug Safety 200716 1195-1202. (doi:10.1002/ pds.1441)

26 Tseng $\mathrm{CH}$. New-onset diabetes with a history of dyslipidemia predicts pancreatic cancer. Pancreas 2012 In press. (doi:10.1097/ MPA.0b013e3182571ba9)

27 McCormack VA \& Boffetta P. Today's lifestyles, tomorrow's cancers: trends in lifestyle risk factors for cancer in low- and middle-income countries. Annals of Oncology 201122 2349-2357. (doi:10.1093/ annonc/mdq763)

28 Memmott RM, Mercado JR, Maier CR, Kawabata S, Fox SD \& Dennis PA. Metformin prevents tobacco carcinogen-induced lung tumorigenesis. Cancer Prevention Research 20103 1066-1076. (doi:10.1158/1940-6207.CAPR-10-0055)

Received 30 April 2012

Revised version received 2 July 2012

Accepted 9 July 2012 